\title{
APLICAÇÃO DE MEDIADORES REDOX NA DESCOLORAÇÃO DE CORANTES UTILIZANDO CALDO ENZIMÁTIDO BRUTO DE Pleurotus sajor-caju PS-2001
}

\author{
F. BETTIN ${ }^{1}$, F. COUSSEAU ${ }^{1}$, K. MARTINS ${ }^{1}$, S. ZACCARIA $^{1}$, \\ M.M. da SILVEIRA ${ }^{1}$ e A.J.P. DILLON ${ }^{1}$ \\ ${ }^{1}$ Universidade de Caxias do Sul, Instituto de Biotecnologia \\ Laboratório de Enzimas e Biomassas - Laboratório de Bioprocessos \\ E-mail para contato: fbettin@ucs.br
}

\begin{abstract}
RESUMO - Corantes são estáveis à luz, à temperatura e ao ataque microbiano, representando compostos recalcitrantes. Na presença de mediadores, alguns corantes resistentes à descoloração podem alcançar níveis relevantes de remoção de cor. Diante disso, neste estudo, avaliou-se o efeito da adição de diferentes mediadores sobre a descoloração de 22 corantes pertencentes aos grupos cromóforos antraquinona, azo e trifenilmetano, utilizando lacases produzidas por Pleurotus sajor-caju PS-2001 em processo submerso. As misturas aquosas contendo solução de corante, mediador e caldo enzimático com $30 \mathrm{U}^{\mathrm{mL}} \mathrm{mL}^{-1} \mathrm{de}$ lacases foram mantidas a $35^{\circ} \mathrm{C}$ durante 168 horas. De uma forma geral, os percentuais de descoloração obtidos com 2,2'-azino-bis(ácido 3etilbenzotiazolina-6-sulfônico) sal diamônio (ABTS) como mediador foram inferiores ao controle para treze corantes testados; os melhores resultados foram obtidos com os mediadores hidroxibenzotriazol (HBT) e siringaldazina (SYR). Os corantes trifenilmetano Brilliant Green (65\%), Malachite Green (64\%) e Bromocresol Green (37\%) mostraram os maiores percentuais de descoloração para esta classe. Resultados satisfatórios também foram obtidos com os corantes antraquinona Reactive Blue 220 (48\%), Acid Green 28 (46\%) e Remazol Brilliant Blue R (37\%), assim como para os azo-corantes Levafix Brilliant Red E-4BA (38\%), Disperse Blue 79 (37\%) e Disperse Orange 30 (33\%), com percentuais de descoloração superiores aos controles, preparados na ausência de mediadores.
\end{abstract}

\section{INTRODUÇÃO}

O uso de corantes em processos das indústrias têxtil, de papel, farmacêutica, cosmética e alimentícia vem sendo empregado há muito tempo e a disponibilidade comercial desses compostos é ampla. Atualmente, cerca de 2.000 tipos de corantes estão disponíveis para a indústria têxtil e estima-se que 10 a $15 \%$ do total de corantes utilizados nos processos de tingimento são descartados nos efluentes. A utilização de microrganismos e/ou enzimas para o tratamento de efluentes têxteis poderia reduzir significativamente o consumo excessivo de água, visto que são consumidos aproximadamente 100 litros de água para processar $1 \mathrm{~kg}$ de material têxtil (Guaratini \& Zanoni, 1999; Rodríguez et al., 1999; Ciullini et al., 2008).

Corantes são compostos potencialmente tóxicos, mutagênicos e carcinogênicos, estáveis à luz, à temperatura, ao desbotamento por exposição ao suor, a produtos químicos e ao ataque microbiano, representando compostos recalcitrantes (Rodríguez et al., 1999; Zilly et 
al., 2002; Wesenberg et al., 2003). Cerca de 90\% dos corantes reativos que passam por lodos ativados saem inalterados ao final do processo e são descarregados diretamente nos rios. $\mathrm{O}$ tratamento desses compostos também ocorre por meio de métodos físicos e químicos, porém, nem todos os corantes são removidos por esses processos e, muitas vezes, geram compostos ainda mais tóxicos após uma degradação parcial (Rodríguez et al. 1999; Munari et al., 2008).

Por serem compostos coloridos, mesmo em baixas concentrações (10 a $\left.50 \mathrm{mg} . \mathrm{L}^{-1}\right)$, corantes são facilmente visíveis a olho nu. Uma pequena quantidade lançada nos efluentes já modifica sua cor e gera problemas, como diminuição do teor de oxigênio dissolvido e da atividade fotossintética pela dificuldade de penetração da luz solar nos corpos d'água, prejudicando os organismos aquáticos (Wong \& Yu, 1999; Yang et al., 2009).

Com base no seu grupo cromóforo, corantes podem ser classificados de acordo com sua estrutura química em diferentes classes. Cerca de 50\% dos corantes industriais produzidos mundialmente pertencem à classe azo, representando o maior grupo de corantes sintéticos, que são amplamente utilizados em processos de tingimento de fibras têxteis; corantes dessa classe apresentam resistência à descoloração, sendo que os subprodutos de sua degradação, principalmente aminas aromáticas, podem ser carcinogênicos ou, ainda, gerar compostos mais tóxicos do que a forma primária do corante (Wong \& Yu, 1999; Selvam et al., 2003; Eichlerová et al., 2006). Outro grupo importante de corantes pertence à classe antraquinona; por serem mais suscetíveis à decomposição, corantes desse grupo também são estudados em misturas com os de outras classes para verificar o efeito na descoloração, pois corantes do grupo cromóforo azo geralmente necessitam de um mediador redox para melhorar a eficiência da descoloração. Dessa forma, corantes que atingem maiores níveis de descoloração podem auxiliar na remoção de cor dos que apresentam maior resistência nesse processo (Munari et al., 2008; Forss \& Welander, 2011). De acordo com Casas et al. (2009), corantes pertencentes à classe trifenilmetano são utilizados em muitos processos de tingimento e apresentam alta toxicidade, sendo prejudiciais à saúde humana, animal e ambiental. Como exemplo, o corante Malachite Green pode causar irritação quando em contato com a pele e gerar lesões oculares; Crystal Violet é tóxico para células de mamíferos e, também, um agente mutagênico. Assim, a remoção de corantes de diferentes grupos cromóforos apresenta grande importância sob os pontos de vista ambiental, científico e biotecnológico (Yang et al., 2011).

Fatores como pH, temperatura, concentração de corante e de enzima, tipo e concentração do mediador influenciam diretamente os processos de descoloração de corantes (Schmitt et al., 2012). Durante a última década, fungos de degradação branca foram estudados com relação à sua capacidade de degradar diversos compostos xenobióticos e poluentes, como é o caso dos corantes (Soares et al., 2002). Dentre os fungos ligninolíticos, o gênero Pleurotus se destaca por ser um grupo cosmopolita de cogumelos com alto valor nutricional, propriedades terapêuticas e diversas aplicações ambientais e biotecnológicas, visto que produzem um sistema enzimático capaz de degradar lignina e transformar hidrocarbonetos policíclicos aromáticos, pesticidas, compostos fenólicos e corantes (Cohen et al., 2002; Selvam et al., 2003). Lacases são enzimas com potencial de utilização nesses processos, pois atuam oxidando anéis aromáticos presentes na estrutura química dos corantes e são capazes de descolorir uma ampla variedade desses compostos (Rodríguez et al., 1999; Abadulla et al., 2000). Diante disso, o objetivo deste trabalho foi avaliar o efeito da adição de mediadores redox, em misturas aquosas, sobre a descoloração de 22 corantes pertencentes aos grupos cromóforos antraquinona, azo e trifenilmetano, utilizando lacases produzidas por Pleurotus sajor-caju PS-2001 em processo submerso. 


\section{MATERIAL E MÉTODOS}

Linhagem - Pleurotus sajor-caju PS-2001, da coleção de microrganismos do IB-UCS, foi mantido em placas de Petri em meio contendo serragem de Pinus spp., $20 \mathrm{~g}$; farelo de trigo, $20 \mathrm{~g}$; $\mathrm{CaCO}_{3}, 2 \mathrm{~g}$; ágar-ágar, $20 \mathrm{~g}$; $\mathrm{H}_{2} \mathrm{O}$ destilada q.s.p. $1 \mathrm{~L}$ (Bettin et al., 2009).

Produção de enzimas em biorreator - $\mathrm{O}$ meio de cultivo continha glicose, $5 \mathrm{~g}$; caseína pura, 1,5 g; ácido benzoico, $100 \mathrm{mg}$; $\mathrm{CuSO}_{4}, 100 \mathrm{mg}$; solução mineral de nutrientes e micronutrientes, $100 \mathrm{~mL} ; \mathrm{H}_{2} \mathrm{O}$ destilada q.s.p. 1 L. Utilizou-se um biorreator com agitação mecânica modelo Biostat ${ }^{\circledR} \mathrm{B}$ (volume operacional de $4 \mathrm{~L}$ ) para a produção enzimática em regime descontínuo, pH 6,5 a $28 \pm 1{ }^{\circ} \mathrm{C}$ durante 90 horas de processo (Bettin et al., 2011).

Mediadores redox - Os três compostos testados como mediadores foram 2,2'-azinobis(ácido 3-etilbenzotiazolina-6-sulfônico) sal diamônio (ABTS - 98\%), hidroxibenzotriazol (HBT - 97\%) e siringaldazina (SYR - 100\% de pureza), preparados em concentrações de 5 mmol. $L^{-1}$ e utilizados nas misturas aquosas em concentração final de $0,1 \mu$ mol. $L^{-1}$.

Corantes - Nos ensaios realizados, foram testados quatro corantes do grupo cromóforo antraquinona (Acid Blue 80, Acid Green 28, Reactive Blue 220 e Remazol Brilliant Blue R), dez do grupo azo (Acid Red 315, Congo Red, Disperse Blue 79, Disperse Orange 30, Disperse Red 324, Levafix Brilliant Red E-4BA, Levafix Golden Yellow E-G, Orange G, Reactive Red 198 e Reactive Yellow 15) e oito do grupo trifenilmetano (Brilliant Green, Bromocresol Green, Bromophenol Blue, Coomassie Brilliant Blue G-250, Gentian Violet, Malachite Green, Methyl Violet e Phenol Red), totalizando 22 corantes.

Atividade de lacases - Determinada pela oxidação do substrato ABTS, em tampão acetato de sódio pH 5,0 a 25 C, durante 90 segundos (Wolfenden e Willson, 1982).

Condições experimentais - As misturas reacionais foram preparadas em frascos Duran de $50 \mathrm{~mL}$ contendo $10 \mathrm{~mL}$ de solução de corante (concentração de $50 \mathrm{mg} \cdot \mathrm{L}^{-1}$ ), $10 \mathrm{~mL}$ de caldo enzimático (atividade de $30 \mathrm{U} \cdot \mathrm{mL}^{-1}$ de lacases) e $0,4 \mathrm{~mL}$ de cada mediador, avaliados separadamente (concentração final de $0,1 \mu \mathrm{mol} . \mathrm{L}^{-1}$ ). Os controles consistiram de misturas aquosas preparadas na ausência de mediadores, contendo somente solução de corante e caldo enzimático. Os recipientes foram mantidos em banho termostático a $35^{\circ} \mathrm{C}$ sem agitação e sem controle de $\mathrm{pH}$, sendo coletados $0,4 \mathrm{~mL}$ de cada frasco (em triplicata) a cada 24 horas durante 168 horas para a medição da absorbância. As leituras foram realizadas no comprimento de onda máximo de absorção para cada corante, determinado após testes de varredura.

Determinação do percentual de descoloração - A Equação 1 foi utilizada para os cálculos do percentual de descoloração (Schmitt et al., 2012), onde Abs inicial corresponde à leitura de absorbância inicial (tempo 0) e $A b s$ final à leitura de absorbância nos diferentes tempos avaliados (de 24 a 168 horas).

Percentual de descoloração $(\%)=\frac{\left(A b s_{\text {inicial }}-A b s_{\text {final }}\right)}{A b s_{\text {inicial }}} \times 100$ 


\section{RESULTADOS E DISCUSSÃO}

Neste trabalho, testou-se o potencial de descoloração de corantes das classes antraquinona, azo e trifenilmetano em misturas aquosas mantidas a $35^{\circ} \mathrm{C}$. Utilizou-se caldo enzimático bruto com atividade de $30 \mathrm{U}_{\mathrm{mL}} \mathrm{m}^{-1}$ de lacases produzido por P. sajor-caju PS-2001 em processo submerso. Foram avaliados os efeitos da adição de três mediadores redox nos processos de descoloração (ABTS, HBT e SYR), sendo que os controles foram preparados na ausência de mediadores, apenas contendo caldo enzimático e solução de corante.

$\mathrm{Na}$ Tabela 1, são apresentados os percentuais máximos de descoloração para os corantes da classe antraquinona na presença dos diferentes mediadores testados, assim como seu respectivo tempo e teste controle, preparado na ausência de mediadores. É possível observar que, para o mediador ABTS, somente Reactive Blue 220 atingiu percentual de descoloração superior ao controle (cerca de 36\%) e Remazol Brilliant Blue R não mostrou descoloração na presença desse composto, diferentemente do que foi observado no seu respectivo teste controle. Para o mediador HBT, apenas o corante Acid Blue 80 atingiu níveis percentuais de descoloração inferiores ao controle; os outros três corantes dessa classe (Acid Green 28, Reactive Blue 220 e Remazol Brilliant Blue R) mostraram valores superiores ao controle, todos acima de $35 \%$. Os resultados obtidos com o mediador SYR foram positivos apenas para Reactive Blue 220 e Remazol Brilliant Blue R, também com níveis percentuais superiores a $35 \%$ de descoloração.

Tabela 1 - Percentual máximo de descoloração de corantes da classe antraquinona após reação de até 168 horas em misturas aquosas contendo diferentes

mediadores redox sem controle de $\mathrm{pH}$ em temperatura de $35^{\circ} \mathrm{C}$

\begin{tabular}{|l|cc|cc|cc|cc|}
\hline \multicolumn{1}{|c|}{ Mediador } & \multicolumn{2}{|c|}{ Controle } & \multicolumn{2}{c|}{ ABTS } & \multicolumn{2}{c|}{ HBT } & \multicolumn{2}{c|}{ SYR } \\
\hline \multicolumn{1}{|c|}{ Percentual de descoloração } & $\%$ & $\mathbf{t}(\mathbf{h})$ & $\%$ & $\mathbf{t}(\mathbf{h})$ & $\%$ & $\mathbf{t}(\mathbf{h})$ & $\%$ & t (h) \\
\hline Acid Blue 80 & 46,8 & 72 & 31,0 & 96 & 38,7 & 24 & 31,2 & 24 \\
Acid Green 28 & 29,2 & 24 & 24,7 & 24 & 46,4 & 24 & 26,3 & 24 \\
Reactive Blue 220 & 31,7 & 72 & 35,9 & 96 & 48,2 & 24 & 35,3 & 24 \\
Remazol Brilliant Blue R & 21,5 & 24 & ND & --- & 36,5 & 168 & 37,0 & 96 \\
\hline
\end{tabular}

ND - Descoloração não observada.

Os dados apresentados na Tabela 2 se referem aos percentuais máximos de descoloração observados para os corantes da classe azo. Verifica-se que, para as misturas aquosas contendo ABTS, os resultados foram superiores ao controle apenas para seis dos dez corantes avaliados, destacando-se Disperse Red 324 e Congo Red, que atingiram níveis de $30 \%$ e $22 \%$ de descoloração, respectivamente. Para o mediador HBT, oito corantes mostraram resultados positivos, evidenciando-se maior diferença com relação ao controle para Acid Red 315, Disperse Orange 30 e Reactive Yellow 15. Nas misturas reacionais contendo SYR, semelhantemente ao que foi observado com HBT, oito corantes também mostraram descoloração superior ao controle, destacando-se Congo Red, Disperse Orange 30, Levafix Brilliant Red E-4BA e Reactive Red 198, com percentuais superiores a 30\%. 
Tabela 2 - Percentual máximo de descoloração de corantes da classe azo após reação de até 168 horas em misturas aquosas contendo diferentes

mediadores redox sem controle de $\mathrm{pH}$ em temperatura de $35^{\circ} \mathrm{C}$

\begin{tabular}{|l|cc|cc|cc|cc|}
\hline \multicolumn{1}{|c|}{ Mediador } & \multicolumn{2}{|c|}{ Controle } & \multicolumn{2}{c|}{ ABTS } & \multicolumn{2}{c|}{ HBT } & \multicolumn{2}{c|}{ SYR } \\
\hline \multicolumn{1}{|c|}{ Percentual de descoloração } & \% & $\mathbf{t}(\mathbf{h})$ & $\%$ & $\mathbf{t}(\mathbf{h})$ & $\%$ & $\mathbf{t}(\mathbf{h})$ & $\%$ & $\mathbf{t}(\mathbf{h})$ \\
\hline Acid Red 315 & 3,97 & 72 & 13,1 & 24 & 26,8 & 24 & 19,6 & 48 \\
Congo Red & 9,48 & 72 & 22,4 & 96 & 20,0 & 168 & 30,7 & 96 \\
Disperse Blue 79 & 14,7 & 24 & 7,18 & 24 & 36,5 & 24 & 24,9 & 24 \\
Disperse Orange 30 & 5,55 & 48 & 14,5 & 24 & 29,6 & 168 & 33,0 & 24 \\
Disperse Red 324 & 13,8 & 24 & 30,4 & 168 & 28,5 & 24 & 16,7 & 24 \\
Levafix Brilliant Red E-4BA & 20,9 & 72 & 5,46 & 24 & 31,5 & 48 & 37,5 & 24 \\
Levafix Golden Yellow E-G & 21,9 & 72 & 22,2 & 96 & 20,0 & 24 & 17,2 & 24 \\
Orange G & 38,3 & 72 & 27,0 & 96 & 21,5 & 24 & 20,8 & 24 \\
Reactive Red 198 & 24,1 & 72 & 10,7 & 24 & 30,2 & 24 & 32,8 & 24 \\
Reactive Yellow 15 & 6,25 & 72 & 7,56 & 24 & 21,6 & 24 & 8,76 & 48 \\
\hline
\end{tabular}

$\mathrm{Na}$ Tabela 3, verificam-se os resultados obtidos com os corantes da classe trifenilmetano. Para o mediador ABTS, apenas dois corantes mostraram descoloração superior ao controle (Bromocresol Green e Phenol Red), sendo que os demais apresentaram níveis inferiores à condição sem mediador; Coomassie Brilliant Blue G-250 não foi descolorido na presença de ABTS. As misturas aquosas contendo HBT foram eficientes para cinco dos oito corantes testados, destacando-se Brilliant Green, com 47\% de descoloração. Para o mediador SYR, também, cinco corantes atingiram percentuais superiores ao controle, sendo que Brilliant Green e Malachite Green mostraram níveis acima de 64\% de descoloração.

Tabela 3 - Percentual máximo de descoloração de corantes da classe trifenilmetano após reação de até 168 horas em misturas aquosas contendo diferentes

mediadores redox sem controle de $\mathrm{pH}$ em temperatura de $35^{\circ} \mathrm{C}$

\begin{tabular}{|l|cc|cc|cc|cc|}
\hline \multicolumn{1}{|c|}{ Mediador } & \multicolumn{2}{|c|}{ Controle } & \multicolumn{2}{c|}{ ABTS } & \multicolumn{2}{c|}{ HBT } & \multicolumn{2}{c|}{ SYR } \\
\hline \multicolumn{1}{|c|}{ Percentual de descoloração } & $\%$ & $\mathbf{t}(\mathbf{h})$ & $\boldsymbol{\%}$ & $\mathbf{t}(\mathbf{h})$ & $\boldsymbol{\%}$ & $\mathbf{t}(\mathbf{h})$ & \% & t (h) \\
\hline Brilliant Green & 42,7 & 72 & 40,7 & 72 & 47,0 & 168 & 64,8 & 168 \\
Bromocresol Green & 20,4 & 72 & 36,5 & 168 & 20,3 & 168 & 21,8 & 72 \\
Bromophenol Blue & 16,1 & 72 & 3,14 & 72 & 16,3 & 168 & 10,3 & 96 \\
Coomassie Brilliant Blue G-250 & 21,5 & 72 & ND & --- & 27,2 & 168 & 23,7 & 24 \\
Gentian Violet & 23,6 & 72 & 15,9 & 24 & 27,5 & 24 & 26,8 & 48 \\
Malachite Green & 63,4 & 72 & 56,7 & 48 & 60,5 & 168 & 64,5 & 72 \\
Methyl Violet & 26,6 & 72 & 13,6 & 24 & 24,4 & 24 & 24,0 & 96 \\
Phenol Red & 9,44 & 72 & 11,2 & 96 & 18,7 & 168 & 5,88 & 48 \\
\hline
\end{tabular}

ND - Descoloração não observada. 
A partir dos resultados apresentados nas Tabelas 1, 2 e 3, para realizar uma avaliação mais precisa da eficiência dos diferentes mediadores testados com relação ao controle, construiu-se a Tabela 4, onde são apresentados os dados médios do percentual de descoloração para os 22 corantes avaliados, independentemente do grupo cromóforo ao qual pertencem. Assim, de acordo com os resultados relatados na Tabela 4, sugere-se que os mediadores redox mais eficientes nos processos de descoloração foram HBT e SYR, com percentuais médios de descoloração em torno de $31 \%$ e $28 \%$, respectivamente. ABTS mostrou percentual médio inferior ao controle, destacando a baixa eficiência de sua aplicação como mediador na descoloração de corantes, nas condições testadas.

Tabela 4 - Percentuais médios de descoloração de corantes das classes antraquinona, azo e trifenilmetano em misturas aquosas contendo diferentes mediadores redox

\begin{tabular}{|c|c|c|c|}
\hline Controle & ABTS & HBT & SYR \\
\hline $23,3 \%$ & $19,5 \%$ & $30,8 \%$ & $27,9 \%$ \\
\hline
\end{tabular}

Rodríguez et al. (1999) relatam que lacases são as principais enzimas envolvidas em processos de descoloração de corantes. Corroborando essa afirmação, Zilly et al. (2002) mostraram que Pleurotus pulmonarius, que produz apenas lacases, foi capaz de descolorir corantes das classes azo e trifenilmetano. Yang et al. (2009) estudaram uma linhagem de Trametes capaz de descolorir vários tipos de corantes sintéticos, incluindo alguns das classes antraquinona, azo e trifenilmetano; todos foram descoloridos com lacase purificada e na ausência de mediadores redox, mas poucos foram completamente removidos.

Grande parte dos estudos sobre a descoloração de corantes não utilizam mediadores redox; porém, alguns trabalhos relatam informações importantes sobre a aplicação de mediadores em processos de remoção de cor. Schmitt et al. (2012) mostraram que HBT e SYR proporcionaram aumento na descoloração de corantes na presença de peroxidases, mas o mesmo efeito não foi observado com lacases, que foram mais eficientes na ausência de mediadores. Bibi e Bhatti (2012) observaram que SYR foi um mediador mais efetivo que ABTS e HBT na descoloração do corante Reactive Black 5 utilizando lacase comercial de Trametes versicolor; outros testes realizados com esse mesmo corante sugerem um grande potencial do sistema lacase-mediador no tratamento de efluentes contendo azo-corantes (Wang et al., 2011). Estudos com compostos-modelo diméricos indicam que os mecanismos de oxidação por ABTS e HBT são diferentes (Bourbonnais et al., 1997), mas a descoloração e a eficiência do sistema lacase-mediador também estão fortemente relacionadas com a estrutura química e a natureza do corante (Mendoza et al., 2011; Schmitt et al., 2012).

Além dos mediadores redox sintéticos, corantes com maior suscetibilidade ao ataque enzimático também podem atuar como mediadores em processos de descoloração. Estudos realizados por Zeng et al. (2012) mostraram que alguns corantes azo, resistentes à descoloração, quando misturados com corantes antraquinona, alcançaram níveis significativos de remoção de cor. Ainda, Munari et al. (2008) também relataram que os azo-corantes Acid Red 315, Disperse Blue 79, Disperse Orange 30, Reactive Red 198 e Reactive Yellow 15, que apresentavam baixa descoloração, quando misturados com o corante antraquinona Reactive Blue 220, alcançaram níveis relevantes de remoção de cor durante o cultivo de $P$. sajor-caju PS-2001, sugerindo que este último corante atuou como mediador redox no processo. 


\section{CONCLUSÕES}

Os resultados deste estudo sugerem que lacases são enzimas eficientes na descoloração de corantes dos grupos cromóforos antraquinona, azo e trifenilmetano em misturas aquosas mantidas a $35^{\circ} \mathrm{C}$ sem controle de $\mathrm{pH}$. Com relação aos mediadores redox avaliados, HBT e SYR são mais efetivos na remoção de cor com relação ao ABTS. Assim, conclui-se que o caldo enzimático bruto com atividade de lacases produzido por P. sajor-caju PS-2001 em processo submerso apresenta potencial para oxidação de uma ampla variedade de corantes, com estruturas químicas diversas, tanto na presença como na ausência de mediadores, de acordo com os resultados observados nos testes controle. Na continuidade dos estudos nessa linha de pesquisa, estão em andamento testes baseados na utilização de diferentes concentrações de ABTS, HBT e SYR, assim como a avaliação de alguns corantes como mediadores redox para a descoloração de corantes mais resistentes ao ataque enzimático.

\section{REFERÊNCIAS}

ABADULLA, E.; TZANOV, T.; COSTA, S.; ROBRA, K.H.; CAVACO-PAULO, A.; GÜBITZ, G.M. Decolorization and detoxification of textile dyes with a laccase from Trametes hirsuta. Appl. Environ. Microbiol., v. 66, p. 3357-3362, 2000.

BETTIN, F.; MONTANARI, Q.; CALLONI, R.; GAIO, T.A.; SILVEIRA, M.M.; DILLON, A.J.P. Production of laccases in submerged process by Pleurotus sajor-caju PS-2001 in relation to carbon and organic nitrogen sources, antifoams and Tween 80. J. Ind. Microbiol. Biotechnol., v. 36, p. 1-9, 2009.

BETTIN, F.; ROSA, L.O.; MONTANARI, Q.; CALLONI, R.; GAIO, T.A.; MALVESSI, E.; SILVEIRA, M.M.; DILLON, A.J.P. Growth, kinetics, production, and characterization of extracellular laccases from Pleurotus sajor-caju PS-2001. Process Biochem., v. 46, p. 758-764, 2011.

BIBI, I; BHATTI, H.N. Biodecolorization of Reactive Black 5 by laccase mediator system. African J. Biotechnol., v. 11, p. 7464-7471, 2012.

BOURBONNAIS, R.; PAICE, M.G.; FREIERMUTH, B.; BODIE, E.; BORNEMAN, S. Reactivities of various mediators and laccases with kraft pulp and lignin model compounds. Appl. Environ. Microbiol., v. 63, p. 4627-4632, 1997.

CASAS, N.; PARELlA, T.; VICENT, T.; CAMINAL, G.; SARRÀ, M. Metabolites from the biodegradation of triphenylmethane dyes by Trametes versicolor or laccase. Chemosphere, v. 75, p. 1344-1349, 2009.

CIULLINI, I.; TILLI, S.; SCOZZAFAVA, A.; BRIGANTI, F. Fungal laccase, cellobiose dehydrogenase, and chemical mediators: Combined actions for the decolorization of different classes of textile dyes. Bioresour. Technol., v. 99, p. 7003-7010, 2008.

COHEN, R.; PERSKY, L.; HADAR, Y. Biotechnological applications and potencial of wooddegrading mushrooms of the genus Pleurotus. Appl. Microbiol. Biotechnol., v. 58, p. 582-594, 2002.

EICHLEROVÁ, I.; HOMOLKA, L.; LISÁ, L.; NERUD, F. Ability of industrial dyes decolorization and ligninolytic enzymes production by different Pleurotus species with special attention on Pleurotus calyptratus, strain CCBAS 461. Process Biochem., v. 41, p. 941-946, 2006.

FORSS, J.; WELANDER, U. Biodegradation of azo and anthraquinone dyes in continuous systems. Int. Biodeterior. Biodegrad., v. 65, p. 227-237, 2011. 
GUARATINI, C.C.I.; ZANONI, M.V.B. Corantes têxteis. Quím. Nova, v. 23, p. 71-78, 1999.

MENDOZA, L.; JONSTRUP, M.; HATTI-KAUL, R.; MATTIASSON, B. Azo dye decolorization by a laccase/mediator system in a membrane reactor: enzyme and mediator reusability. Enzyme Microb. Technol., v. 49, p. 478-484, 2011.

MUNARI, F.M.; GAIO, T.A.; CALLONI, R.; DILLON, A.J.P. Decolorization of textile dyes by enzymatic extract and submerged cultures of Pleurotus sajor-caju. World J. Microbiol. Biotechnol., v. 24, p. 1383-1392, 2008.

RODRÍGUEZ, E.; PICKARD, M.A.; VAZQUEZ-DUHALT, R. Industrial dye decolorization by laccases from ligninolytic fungi. Curr. Microbiol., v. 38, p. 27-32, 1999.

SCHMITT, S.; SOUZA, R.; BETTIN, F.; DILLON, A.J.P.; VALLE, J.A.B.; ANDREAUS, J. Decolorization of aqueous solutions of disperse textile dyes by oxidoreductases. Biocatal. Biotransform., v. 30, p. 48-56, 2012.

SELVAM, K.; SWAMINATHAN, K.; CHAE, K.S. Decolourization of azo dyes and a dye industry effluent by a white rot fungus Thelephora sp. Bioresour. Technol., v. 88, p. 115-119, 2003.

SOARES, G.M.B.; AMORIM, M.T.P.; HRDINA, R.; FERREIRA, M.C. Studies on the biotransformation of novel disazo dyes by laccase. Process Biochem., v. 37, p. 581-587, 2002.

WANG, T.N.; LU, L.; LI, G.F.; LI, J.; XU, T.F.; ZHAO, M. Decolorization of the azo dye reactive black 5 using laccase mediator system. African J. Biotechnol., v. 10, p. 17186-17191, 2011.

WESENBERG, D.; KYRIAKIDES, I.; AGATHOS, S.N. White-rot fungi and enzymes for the treatment of industrial dye effluents. Biotechnol. Adv., v. 22, p. 161-187, 2003.

WOLFENDEN, B.S.; WILLSON, R.L. Radical-cations as reference chromogens in the kinetic studies of one-electron transfer reactions: pulse radiolysis studies of 2,2'-azinobis-(3-ethylbenzthiazoline6-sulphonate). J. Chem. Soc. Perkin Trans. II, v. 02, p. 805-812, 1982.

WONG, Y.; YU, J. Laccase-catalyzed decolorization of synthetic dyes. Water Res., v. 33, p. 3512$3520,1999$.

YANG, X.; WANG, J.; ZHAO, X.; WANG, Q.; XUE, R. Increasing manganese peroxidase production and biodecolorization of triphenylmethane dyes by novel fungal consortium. Bioresour. Technol., v. 102, p. 10535-10541, 2011.

YANG, X.Q.; ZHAO, X.X.; LIU, C.Y.; ZHENG,Y.; QIAN, S.J. Decolorization of azo, triphenylmethane and anthraquinone dyes by a newly isolated Trametes sp. SQ01 and its laccase. Process Biochem., v. 44, p. 1185-1189, 2009.

ZENG, X.; CAI, Y.; LIAO, X.; ZENG, X.; LUO, S.; ZHANG, D. Anthraquinone dye assisted the decolorization of azo dyes by a novel Trametes trogii laccase. Process Biochem., v. 47, p. 160-163, 2012.

ZILLY, A.; SOUZA, C.G.M.; BARBOSA-TESSMANN, I.P.; PERALTA, R.M. Decolorization of industrial dyes by a brazilian strain of Pleurotus pulmonarius producing laccase as the sole phenoloxidizing enzyme. Folia Microbiol., v. 47, p. 272-277, 2002.

Apoio: FAPERGS, CAPES, CNPq e UCS. 